\title{
I HOPE THEY DON'T GET FORGOTTEN. A DESCRIPTIVE CORPUS-BASED APPROACH TO GET-PASSIVES WITH VERBS OF COGNITION IN ENGLISH
}

\author{
Luisa González Romero \\ Universidad de Huelva
}

\begin{abstract}
It is widely held in the literature that English get-passives are only found with dynamic predicates, stative verbs being excluded from it. However, based on an extensive corpusbased analysis of occurrences with the verbs forget, know, remember, understand and believe, this article shows that the get-passive with stative verbs of cognition, although infrequent, does occur in English. The so-called cognitive get-passive is then examined in relation to the formal, semantic and pragmatic properties commonly claimed to define central get-passives with dynamic verbs. The analysis reveals, on the one hand, that these features are not equally relevant in the characterisation of these sentences and, on the other, that there exist strong interconnections between them and the lexical properties of the verbs analysed.
\end{abstract}

KEYWORDS: English language, corpus analysis, passive voice, get-passive, verbs of cognition

I hope they don't get forgotten. Un estudio descriptivo basado en corpus de la pasiva con get con verbos de cognición en inglés

RESUMEN: En los estudios sobre la pasiva con get en inglés, la idea de que esta construcción solo admite verbos dinámicos, no siendo aceptables las oraciones formadas con verbos estativos, está ampliamente extendida. No obstante, a partir del análisis de un extenso corpus de pasivas con get con los verbos forget, know, remember, understand y believe, este estudio demuestra que esta estructura, aunque infrecuente, es posible en inglés con verbos estativos de cognición. Asimismo, la construcción se analiza en relación con las características formales, semánticas y pragmáticas que distinguen a la pasiva con get prototípica. El análisis revela, por un lado, que estas propiedades no presentan la misma relevancia en la caracterización de estas oraciones y, por otro, que existen fuertes conexiones entre ellas y los rasgos léxicos de los verbos analizados.

PALABRAS CLAVE: lengua inglesa, análisis de corpus, voz pasiva, pasiva con get, verbos de cognición 


\section{INTRODUCTION}

The analysis of passive sentences with the verb get in English has been approached from many different perspectives over the years. Among them, the main areas of research have been register and style (Rühlemann, 2007; Anderwald, 2017; Phoocharoensil, 2020), regional and social distribution (Collins, 1996; Coto Villalibre, 2015a, 2015b), origin and diachronic development (Givón and Yang, 1994; Yonekura, 1999; Hund, 2001; Fleisher, 2006), possible relation with the middle voice (Arce Arenales et al., 1994; Mitkovska and Bužarovska, 2012), and the semantic and pragmatic features that distinguish it from the regular be-passive (Collins, 1996; Downing, 1996; Wanner, 2013, among others). From a structural point of view, there is a consensus that core or central get-passives, as illustrated in (1a), exhibit the following defining features: a lexical verb with dynamic meaning, a be-passive counterpart (1b), a corresponding active equivalent (1c), and an explicit or (most usually) implicit byphrase (1d):
(1a) James got caught.
(1b) James was caught.
(1c) The police caught John.
(1d) James got caught by the police.

Despite the extensive body of literature devoted to its analysis, some of the conditions that govern the use of the get-passive still remain elusive. The first property mentioned above, for instance, seems to exclude stative predicates from the get-passive. In fact, several authors such as Chappell (1980), Huddleston and Pullum (2002), Alexiadou (2005), Wanner (2009) or Kim (2012), among others, agree on the idea that only dynamic verbs are allowed in these sentences. According to Alexiadou (2005, 17), the subject of the get-passive must be interpreted as affected, a property which the internal argument of stative verbs lacks. For Huddleston and Pullum (2002, 1442), the obligatory presence of a dynamic verb in getpassives is required by the dynamic nature of get in its other uses. Consequently, examples such as (2)-(4) with stative verbs of perception, emotion or cognition are often reported as unacceptable:

\footnotetext{
(2) *Mary got seen. (Alexiadou, 2005, 17)

(3) *The teacher got liked by everybody. (Kim, 2012, 5)

(4) *The C.I.A. got believed to be the source of information. (Chappell, 1980, 421)
}

At first sight, this restriction on the use of the get-passive may be supported by the fact that the search in the British National Corpus (BNC) for combinations of get with the past participle of common stative verbs such as understand, believe or like returns no results. However, get-passives with verbs from these semantic classes have occasionally been attested: 
(5) [...] 14 billion videos get seen on YouTube every month. (Thompson et al., 2013, 2)

(6) [...] working so desperately hard to get liked by the public. (Downing, 1996, 189)

(7) After a lot of pushing in commercials, the claim of Zotz, the miracle detergent, finally got believed. (Lakoff, 1971, 157)

The verbs in (5)-(7) belongs to the class of 'mental verbs' which, in Biber et al.'s (1999, 362 ) words, "denote a wide range of activities and states experienced by humans; they do not involve physical action and do not necessarily entail volition". Because of their lack of dynamicity, one of the most obvious differences between this verbal class and the dynamic verbs that typically appear in get-passives is the semantic role of the participants in the process: whereas dynamic verbs usually feature an agent and a patient (or theme, depending on the terminology used), mental verbs are typically associated with an experiencer and a phenomenon. Following Langacker (1991, 236), the experiencer can be defined as "an individual engaged in some type of mental process, be it intellectual, perceptual or emotive". The role phenomenon corresponds to the second participant in the mental process: "that which is felt, thought, wanted or perceived" (Halliday and Mathiessen, 2004, 203).

Except for a few exceptions such as Downing (1996), Thompson et al. (2013) or Thompson and Scheepers (2013), who argue that these sentences are possible but do not explore them any further, these instances of the get-passive have gone unnoticed in earlier studies. In view of this gap, the first goal of this work is to show that, contrary to the mainstream opinion, stative verbs of cognition are indeed compatible with the get-passive. By means of an extensive corpus analysis, my second purpose is to establish whether and to what extent these sentences, which will be called cognitive get-passives from now on, display the syntactic, semantic and pragmatic features commonly associated with the central get-passive and absent from the regular be-passive. The findings obtained are likewise expected to shed some light on the proper characterisation of the get-passive as a whole, a phenomenon which has been sometimes regarded as "a linguistic puzzle" (Carter and McCarthy, 1999, 54).

This article is organized as follows. In section 2, I will give details about the source of the data used in the analysis and the corpora chosen for its compilation. Section 3 will focus on the analysis of the ingressive and resultative semantic components and the aspectual feature of telicity exhibited by the get-passive, which will turn out to be the key factor in the characterization of the construction. The following sections will look into the additional semantic and pragmatic features commonly associated with the construction in the literature. Thus, in section 4, I will investigate the notion of partial or secondary responsibility usually assigned to the subject, and it will be argued that this feature can be also found in other participants in the situation. ${ }^{1}$ Section 5 will deal with the distribution of human and inanimate subjects in get-passives whereas in section 6 the usual absence of an explicit by-phrase will be

${ }^{1}$ For the sake of clarity, the term 'subject' will be used throughout this work to refer both to the syntactic function in the sentence as well as to the real-world referent of this clause element when discussing their semantic and pragmatic features. 
examined. In sections 7 and 8, I will analyse the adversity reading and the emotional involvement of the speaker commonly associated with the construction in the literature. Finally, section 9 will provide a summary of the main findings and some final remarks on the cognitive get-passive.

\section{THE CORPUS}

In order to achieve the aims stated above, five verbs from the semantic domain of cognition - forget, know, remember, understand and believe - have been examined. Taking into account the apparent rarity of this phenomenon and the fact that the corpora used in previous works may have been not large enough to provide evidence of the actual occurrence of this pattern, this study is based on data extracted from the News of the Web Corpus (NOW) (Davies, 2016) which, at the time of writing this paper, consists of 10.3 billion words from web-based newspapers and magazines in twenty English-speaking countries. ${ }^{2}$

Together with its large size, another crucial reason for choosing this corpus has been the fact that it contains data from 2010 to the present time and is constantly growing. This feature of the NOW corpus is extremely relevant in this work because the use of the get-passive has been reported to have increased from the 1960s on (see Hundt, 2001; Mair and Leech, 2006; Leech et al., 2009; Kim, 2012; Anderwald, 2017, among others). It is expected, therefore, that the more recent the data compiled in the corpus, the more likely documenting the pattern under investigation will be and the more frequently it will occur.

After searching for the lemma GET immediately followed by the past participle of the verbs selected and filtering out repeated tokens and occurrences where the participle was followed by a preposition other than by, as in get known as or get forgotten about, in order to ensure that the active counterpart is invariably monotransitive for all the tokens, 1163 occurrences were collected. As for the temporal span, the search covered from 2010 to December 2019. Figure 1 presents the number of instances for each verb in the corpus.

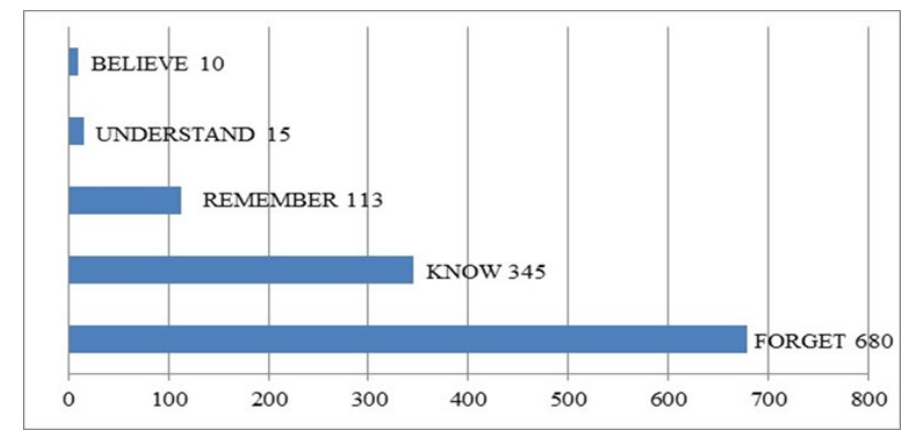

Figure 1. Number of occurrences of get-passives with the verbs believe, understand, remember, know and forget in the corpus

${ }^{2}$ Since this paper is primarily aimed to prove the existence of the cognitive get-passive in English and to provide a general description of its distinctive properties, no distinction will be made as regards the national variety from which the data comes from. 
If the number of tokens in the corpus is considered in relation to the total amount of data contained in the NOW corpus, it is evident that get-passives with verbs of cognition are extremely rare, but undoubtedly possible in PDE.

\section{INGRESSIVE AND RESULTATIVE MEANINGS}

\subsection{Aspectual features of central get-passives}

A frequent claim in the literature on the passive voice in English states that while bepassives may be ambiguous between a stative and a dynamic reading, get-passives are always dynamic (see Jespersen, 1949; Hatcher, 1949; Palmer, 1988, or Biber et al., 1999). Quirk et al. $(1985,162)$ note in this regard that the get-passive is a useful device to replace the be-passive when an actional interpretation is intended: the potential ambiguity of a sentence such as The chair was broken is neutralised by the dynamic nature of The chair got broken.

It is also widely held that the dynamicity of the get-passive is rooted in the ingressive and resultative character of this construction. Authors such as Palmer $(1988,89)$ and Biber et al. $(1999,481)$ agree on the idea that get-passives describe the process of the subject arriving or getting into the resultant state denoted by the participle. Fleisher $(2006,237)$ argues that the get-passive denotes an event triggering the onset of a result state, and for Quirk et al. (1985, 161) and Lindstromberg $(1991,293)$ this construction puts the emphasis on the result of the event. It is precisely this focus on the result of the action that some authors take to be one of the most relevant features of the central get-passive. In this regard, Vanrespaille $(1991,97)$ claims that the get-passive "conveys the sense of an action leading up to a significant result which is sometimes felt as irreversible".

Kim $(2012,6)$ also claims that get-passives convey the meaning of "arrive at a resultant state". A direct consequence of this property is, according to Kim, that the events that getpassives denote have an endpoint, being therefore telic. Martínez Vázquez $(1989,194)$ reaches the same conclusion when she notes that get-passives express processes with an endpoint after which they cannot develop any further since they imply a change of state. The notion of 'telicity' and the contrast between the features telic and atelic is a core distinction in the characterization of 'lexical aspect', also known as 'Aktionsart' (Vendler, 1957), 'situation types' (Smith, 1991), or 'ontological aspect' (Declerk et al., 2006), to name just a few terms used in the literature. While grammatical aspect involves "different ways of viewing the internal temporal constituency of a situation" (Comrie, 1976, 3), lexical aspect "concerns the classification [...] of states of affairs or occurrences in terms of their temporal properties" (Binnick, 2006, 244). Among these properties, stativity, telicity or durativity are probably the most recurrent in the different aspectual classifications proposed.

A common diagnosis to tell telic and atelic situations apart is the use of time adverbials with in-phrases, only acceptable when the situation is telic, and for phrases, which are 
restricted to atelic processes. The contrast in (8), from Kim $(2012,7)$, shows that get-passives are telic constructions:

(8) John got promoted in two years $/{ }^{*}$ for two years.

Another widely used test to determine whether a situation is telic or atelic involves progressive tenses: when a sentence in the progressive implies the same situation referred to in a perfect form, the situation is atelic; otherwise, it is telic. After applying this test to the getpassive, Martínez Vázquez $(1989,194)$ observes that the resulting sentence does not entail that the action has been completed, which again confirms that get-passives are telic:

\section{(9) I was getting elected $\neq$ I had been elected}

Both Martínez Vázquez $(1989,195)$ and $\operatorname{Kim}(2012,12)$ conclude that the telic nature of the get-passive imposes an aspectual constraint on the verbs that can appear in the construction. However, whereas the former claims that the get-passive is incompatible with atelic situations, the latter suggests that the construction simply favours telic verbs but does not forbid the occurrence of atelic predicates. When this happens, though, they are coerced into "telic eventualities in which the subject reaches a culminating point, caused by the action involved" (Kim, 2012, 12).

Recent diachronic corpus analyses carried out by Schwarz (2017 and 2019) in relation to the situation types preferences of the get-passive support Kim's and Martínez Vázquez's proposal on the telic nature of get-passives and its ensuing tendency to select telic predicates. With the aim of finding signs of 'semantic bleaching' (ie., loss of semantic restrictions) which might indicate that the get-passive is undergoing a process of grammaticalization, Schwarz uses in her analyses five of the situation types described by Quirk et al. (1985). On the basis of the contrasts durative/punctual and conclusive/non-conclusive, the following situation types are adopted: 'accomplishment' (durative/conclusive); 'activity' (durative/non-conclusive); 'transitional act' (punctual/conclusive), and 'momentary act' (punctual/non-conclusive). ${ }^{3}$ A fifth type where these contrasts do not apply, stative, is also included.

After analysing an extensive corpus of get-passives composed of data from the 1920 s to the 2000 s extracted from the TIME Magazine Corpus, Schwarz $(2017,321)$ finds out that the get-passive shows a strong preference for transitional acts until the end of the $20^{\text {th }}$ century, when she observes a significant increase of the situation type accomplishment parallel to a decrease in the number of transitional acts. These results are corroborated by additional data from the Corpus of Historical American English (COHA), where Schwarz finds that in between

3 Quirk et al. (1985) also include a third opposition, [agentive/nonagentive], in their original proposal. As a result, eight dynamic situation types are recognized. In the simplified version adopted by Schwarz, only the situation types which exhibit the feature [agentive] are considered. On the other hand, Schwarz uses the term 'conclusiveness' as synonym to 'telicity' to refer to "whether or not the action has a natural end point” (Schwarz, 2017, 317). 
the 1980 s and 2000 s accomplishments are as frequent as transitional acts. The strong association of get-passive with conclusive (ie., telic) situation types is further confirmed in Schwarz (2019). This second diachronic corpus analysis based on material from the1870s to 1990s retrieved from COHA shows that "it was not necessarily the use of Transitional Acts that was undergoing change in the get-passive, as suggested in Schwarz (2017), but instead the distribution of conclusive vs. non-conclusive situation-types" (Schwarz, 2019, 200).

The explanation for the preference of get-passives for transitional acts in particular and conclusive (or telic) situation types in general is to be found, according to Schwarz (2017, 325; 2019, 210), in the origin of the construction as proposed by Fleisher (2006): if get-passives developed from inchoative get + adjectives structures such as get sick, which denote the beginning of a new action or state, and thus originated as change-of-state constructions, their association with conclusive situation types is expected. Verbs of the category of transitional acts were the first to appear in the get-passive since they are the most similar to the original get + adjective construction in denoting a punctual change of state; this situation type was then followed by accomplishments, which denote a durative process and a subsequent change of state.

Notwithstanding this preference for telic situation types, it is worth emphasising that the two atelic categories, activities and momentary acts, do also appear in the get-passive, although their proportion is comparatively low. Finally, although Schwarz $(2019,209)$ reports that verbs of the category stative are virtually non-existent in the get-passive, their presence, as clearly shown by our corpus, cannot be excluded. 4

\subsection{Aspectual features of cognitive get-passives}

Turning now to cognitive get-passives, some authors have argued that it is the ingressive and resultative character of the get-passive and its emphasis on the outcome of the action that prevent stative verbs from appearing in this construction. Hatcher (1949) and Vanrespaille (1991), for instance, contend that the get-passive in incompatible with both states and durative actions because this meaning is "inherently absent" with these situation types (Vanrespaille, 1991, 97). Notwithstanding this claim, Downing (1996) suggests that this sense of change of state with a significant result is what licenses the few occurrences of the getpassive with mental verbs of perception, cognition and emotion that she finds in her corpus. Thus, in the get-passives with the stative verbs hear, know and love in (10)-(12), the meaning “appears to be primarily 'come to be X-ed”" (Downing, 1996, 189):

(10) We had to shout very loud to get heard.

4 In the TIME Magazine corpus analysed by Schwarz (2017), transitional acts account for $54 \%$ of the total number of instances, accomplishments represent $24 \%$, and activities and momentary acts add up to $11 \%$ each. Stative verbs, with 5 examples in a corpus 445 tokens, are less than 1 percent of the total. 
(11) It is like any other profession, you get known for being good at what you do.

(12) ... some people don't get loved or taken care of ...

Regarding central get-passives, Downing (1996, 185) stresses that the notion of resultativeness does not always imply resulting state and that the idea of result is mostly implicit rather than overtly expressed in most of the instances in her corpus. 5 Based on the data analysed here, the meaning related to the idea of the subject "coming to be X-ed" is always present in the cognitive get-passives analysed but, according to the context, the idea of result is usually just implied, as in (13), or sometimes more openly stated, as in (14), due to the presence on the locative prepositional phrase in a moldy archive:

(13) In the age of digital reporting, before the truth gets known, the virality takes over.

(14) She never had to worry about whether her playing days would get forgotten in a moldy archive.

The ingressive and resultative nature of get makes it very close to become. Jespersen $(1949,366)$ notes that the beginning of a new state or action is typically implied by the passive of becoming with get and become. Downing $(1996,183)$ pinpoints the similarity between these verbs when she defines the get-passive as "a hybrid, sharing features of a true passive and of a copula of becoming". This closeness is apparent in some tokens in the corpus where both verbs are used to convey the same idea of change and result:

(15) Most of the facts acquired by students tend to get forgotten or become irrelevant with the passage of time.

Close inspection of the corpus of cognitive get-passives suggests that they also exhibit the aspectual properties of central get-passives described in section 3.1. Even though cognitive get-passives are formed out of stative verbs which, by definition, denote atelic situations, they display the typical behaviour of telic construction as regards the tests for telicity mentioned above. The following occurrences from the corpus show that they select temporal in-phrases and that the use of the progressive does not imply that the endpoint of the situation has been achieved:

(16) Such tragedies will keep happening and will get forgotten in few days.

(17) If you are not getting asked to do television shows [...], you are getting forgotten.

Another test to distinguish telic and atelic verbs involves using them in the string It took/will take me an hour..., which, according to Declerk et al. (2006, 62), "measures the

5 However, Guerrero Medina $(2009,274)$ claims that the idea of 'resulting state' conveyed by central get-passives can be coded by a resultative adjective phrase referring to the subject, as in Yes, the good old US fifties, where trade unionists got shot dead for striking in Detroit. 
duration of the actualizing of the situation up to its inherent point of completion". This test, however, appears to be restricted to those verbs with an agentive subject. Several instances of this expression have been attested in the corpus, but only in combinations of passive get and the verb know which, as will be shown in section 4.1., allows for the subject to be interpreted as acting volitionally to enter into the state of being known:

(18) I'm becoming a character actor rather than a movie star [...] It takes you longer to get known, but it gives you more longevity. That's the route I want to go.

(19) The 42-year-old doctor admits his practice has been fairly quiet so far, but agreed it takes time to get known.

The findings set forth by Kim (2012), Schwarz (2017 and 2019), and our own corpus data show that, from an aspectual point of view, the get-passive is not restricted to any situation type in particular although it displays a clear preference for telic predicates. It appears that verbs describing telic situations, both durative and punctual, are largely preferred over atelic situations. Among atelic types, even states are possible though highly infrequent. It can be argued that the reason for this strong association between the get-passive and the notion of telicity is the intrinsic ingressive and resultative meanings of the construction, which provide it with an inherent telic sense. Due to this telic nature of the get-passive, verbs that denote events which convey a culminating point are perfect candidates to be found in it. Atelic verbs, including stative predicates such as the verbs of cognition analysed here, may also be possible with passive get since, as Kim (2012) proposes, the construction displays a coercion effect that makes atelic predicates denote processes with a culminating point. This culminating point is not, as in the case of telic verbs, a natural endpoint, but the resulting state reached by the subject due to the action - or mental process in the case of verbs of cognition- involved.

\section{ASSIGNMENT OF RESPONSIBILITY IN COGNITIVE GET-PASSIVES}

\subsection{Secondary responsibility of the subject}

The patient's partial or secondary responsibility in the event is probably one of the most frequently cited features of central get-passives. Hatcher $(1949,436)$ suggests that in these constructions the agent has a subordinate role in the sense that they do not completely dominate the situation since the patient has the chance to modify or determine in some way what happens to them. Toyota $(2007,148)$, who distinguishes three types of get-passives in PDE with distinct syntactic and semantic properties, argues that "beyond the differences, there is one common denominator, viz. subject's responsibility" and adds that this feature is "the basic characteristic of the get-passive". This frequent claim about the subject's responsible role in the action is supported by recent psycholinguistic research carried out by Gotowski (2016), who shows that, despite the higher preference for be-passives in general probably due to prescriptive reasons, native speakers are more likely to select get-passives in 
contexts where the subject is understood as somehow responsible for the outcome of the event.

The responsibility reading of central get-passives is easy to observe in sentences with a human subject. Downing $(1996,198)$ argues that, although a true agent must have acted deliberately, the action expressed can be attributed to the subject's good fortune (20), to their efforts in causing the action (21), or, when the outcome is negative, to misbehaviour, carelessness or simply bad luck (22):

(20) He started to get appointed to Royal Commissions.

(21) If we are going to have any chance of getting invited to his party tomorrow night...

(22) He got shot trying to escape.

When the subject is inanimate, its responsibility may be related, according to Downing (1996, 199), to some positive or negative feature that may have an influence on the action, such as the small size of the print in (23), or to its spatial or temporal location, as in (24):

(23) The fine print sometimes gets neglected.

(24) Would the Post Office get flooded?

In some contexts, responsibility is linked to some human associated with the inanimate subject, usually its creator or owner. This implication, pointed out by Lakoff $(1971,154-55)$ or Chappell (1980, 440-41), among others, is clear in the following instance from the latter:

(25) Jane's bike got stolen yesterday. (She always forgets to lock it up).

The analysis of the corpus of cognitive get-passives supports previous views on the responsibility reading of these sentences. As can be seen in Figure 2, except for forget, there is a sense of partial responsibility attached to the subject in most of the examples.

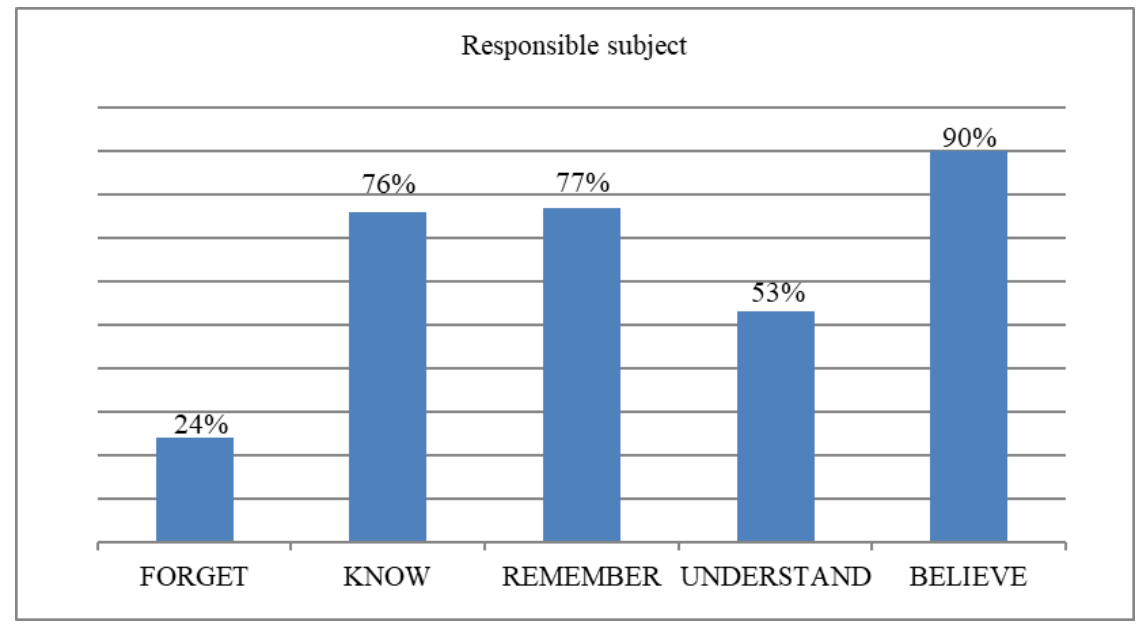

Figure 2. Distribution of partially responsible subjects in the corpus 
As in central get-passives, most instances of cognitive get-passives with human subjects depict situations where some feature of this participant has a direct, yet many times unintentional, influence on the development of the cognitive process denoted. Although sometimes it must be inferred from the context, this feature is frequently overtly expressed in the sentence. The conditional clauses in (26) and the description of children as having no say in many issues in (27) are clear contextual clues of how both subjects are portrayed as partially responsible for what happens to them:

(26) If you play well, you get remembered; if you don't play well you still get remembered.

(27) Children don't have a voice in the same way adults and seniors have. They are not voters and they can easily get forgotten.

In other instances, the subject takes part in the process intentionally and volitionally, showing thus a higher degree of responsibility and control. The use of the verb want in (28) and the noun target in (29) illustrates their active and purposive involvement:

(28) I want to score and help the team win on Saturday because that is how you get remembered [...], scoring goals in the big games.

(29) This is my first target, to get known by every player [...].

The presence of a fully responsible subject is especially frequent in get-passives with the verb know, where more than half of the human subjects act on purpose to become known.

As regards inanimate subjects, cognitive get-passives mirror central constructions since secondary responsibility can be also related to some internal or external feature of the subject, as in (30)-(31), or is associated to the human being who owns or creates the object denoted, as in (32)-(33):

(30) Stickers have something magic that gets understood immediately.

(31) [...] stories that are so funny, so interesting, so unusual, or so emotional that they attract attention, change perceptions, and get remembered.

(32) [...] when I buy cherry or grape tomatoes they tend to get forgotten in the back of the fridge after a couple of salads (or whatever I bought them for).

(33) He was essentially asking me how do I innovate in statistics such that it gets known, understood and used.

The data examined so far appears to confirm the close link between the cognitive getpassive and the notion of subject's responsibility, but it has also shown that this meaning does not appear in all the examples analysed. 


\subsection{Other sources of secondary responsibility in cognitive get-passives}

Notwithstanding the lack of a clear responsible subject in some instances of the corpus, an overtone of control, contribution or participation in the situation is not still completely absent since many of them convey a sense of direct involvement of the other participants in the cognitive process denoted.

In some tokens, responsibility shifts from the subject to the second participant in the process, the experiencer, who is most usually implicit. In the following examples, the development of the situation is presented as depending exclusively on the experiencer, with no implication of the subject being active or passively involved in causing it:

(34) The trouble is that the public usually only hears the bad news. Successes get forgotten.

(35) What gets remembered is determined by who is in the room doing the remembering.

Although it is unusual to find references to this meaning in the analysis of central getpassives, Lakoff $(1971,155)$ points out that get "sometimes suggests responsibility on the part of the underlying (not superficial) subject" and relates this implication to the expression of the speaker's attitude, usually negative, towards the event described. In line with Lakoff's observations, notice how the example in (35) gives a glimpse of the speaker's discontent with the situation.

As for our corpus, the reading which assigns the responsibility for causing the event to the experiencer has not been attested with the verb know and has been found only occasionally with remember and believe, but is particularly frequent with forget and, to a lesser extent, with understand, as Figure 3 shows.

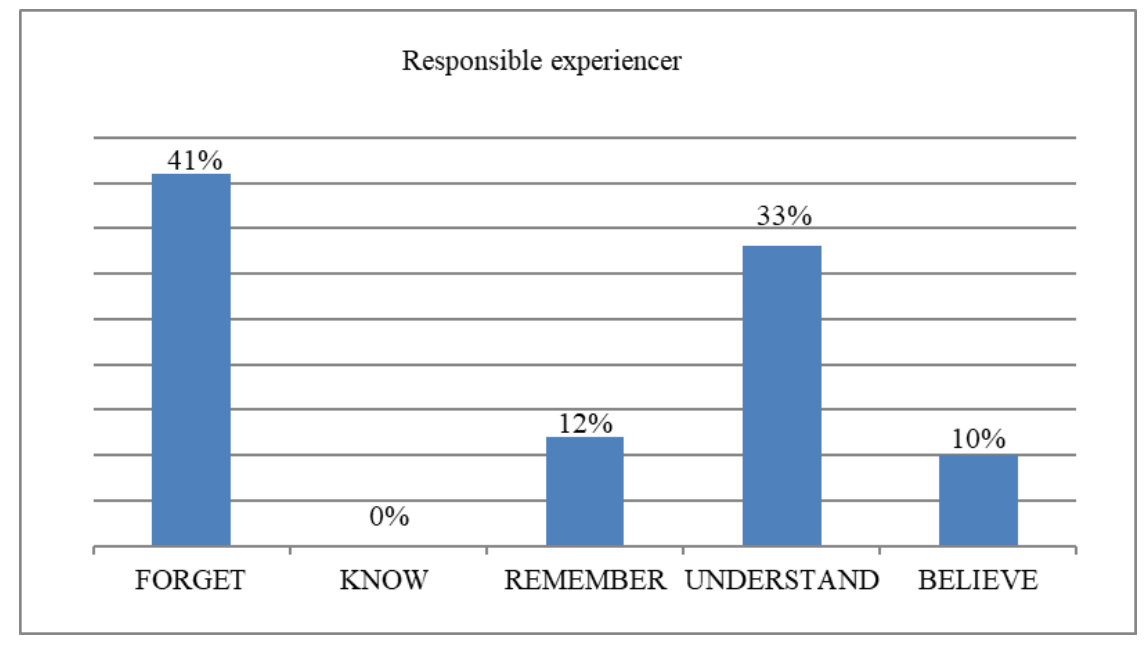

Figure 3. Distribution of responsible experiencers in the corpus

In some other occurrences, the reason for the process to take place seems to be some external circumstance not directly related either to the subject or to the implicit experiencer 
and which stands beyond their control. Sometimes, the circumstance which prompts the event may be explicit in the sentence, as in (36), or just implied, as in (37):

(36) Kadazandusun cuisine is getting known internationally thanks to the venerable Malaysian custom of being hospitable.

(37) While even the most organised among us might do everything we can do to keep the track of these, there are times when dates or events inevitably get forgotten.

Figure 4 shows that once again the verbs examined do not exhibit a parallel behaviour: while around one out of five occurrences with forget implies that something external to the subject is responsible for the process, this reading is rather infrequent with remember and know, and has not been attested with understand and believe.

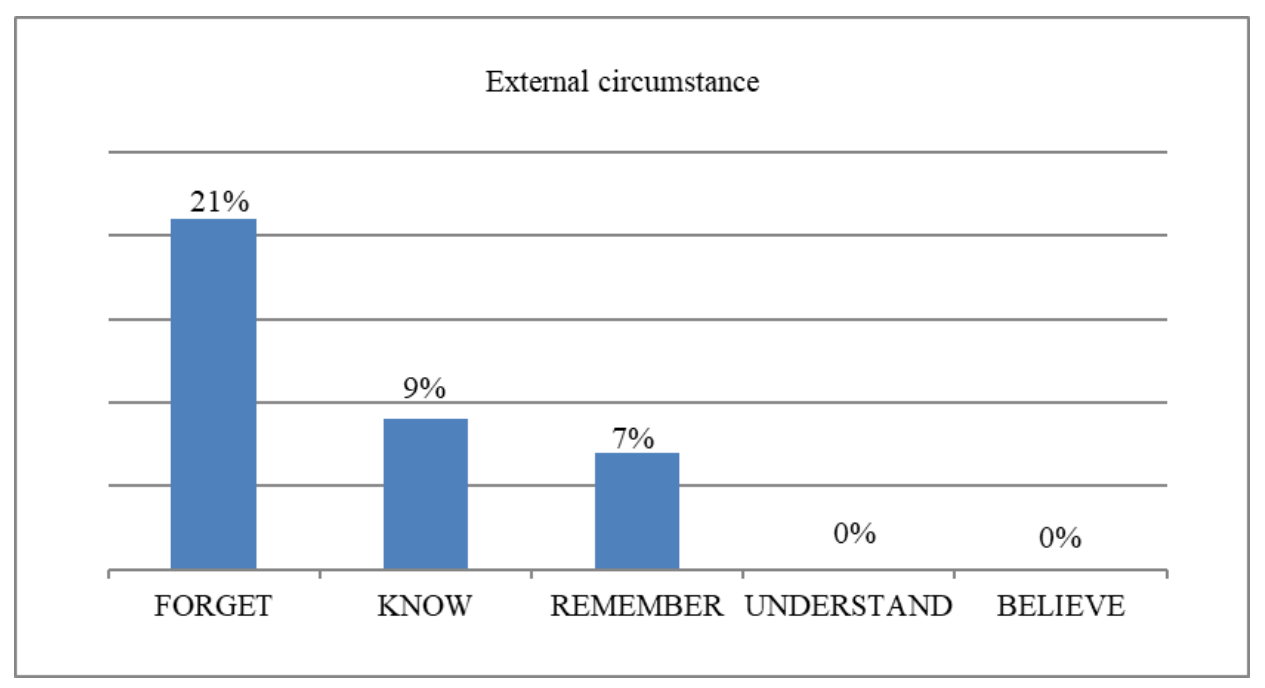

Figure 4. Distribution of tokens where responsibility is linked to an external circumstance

Although up to this point the analysis has shown that there are differences among the verbs analysed regarding the assignment of responsibility to either the subject, the experiencer or some external circumstance, it can be concluded that cognitive get-passives display an obvious tendency to convey an implication of someone or something being partially responsible or, at least, directly involved in the development of the cognitive process denoted.

This sense of secondary responsibility of the participants in the process is by no means incompatible with the ingressive and resultative values that, as shown in section 3 , characterise get-passives; on the contrary, the former usually complements the latter: all cognitive get-passives denote the resulting state reached by the subject after the cognitive process depicted by the participle takes place; additionally, most of them includes the implication of the subject and, to a lesser extent, the experiencer of the process or some other external circumstance being somehow responsible for bringing it about. The following instances illustrate this overlap: 
(38) If you're accurate, you get believed, even trusted.

(39) Many point the finger and blame their partner, rather than communicate how they feel, so they do not get understood for how they're feeling but perceived as being moody.

(40) Every day I made 10 mistakes, so it's about making sure that five of them go undiscovered, two you fix, and the three others get known.

(41) Names of familiar people will get forgotten, people forget their way around, days, dates, season, year, festivals, anniversaries [...].

(42) The longer a series goes the more it gets remembered.

In (38) and (39), the cognitive events and subsequent resulting states depicted are triggered by the subject themselves, either because they have some remarkable feature or have behaved in a way which makes the experiencer be, or not be, engaged in the processes of believing and understanding. In (40), the human being associated with the subject, the person who makes the mistake, is presented as responsible for it becoming known. In (41), the experiencer is depicted as the unwilling responsible for the forgetting process due to the devastating effects of dementia. Finally, the reason why the subject becomes remembered in (42) is a temporal circumstance external to it.

\subsection{Lack of responsibility in cognitive get-passives}

The analysis in sections 4.1 and 4.2 has shown that the meaning of secondary responsibility of the subject or some other participant or circumstance surrounding the situation is widely attested in the corpus. However, this notion does not appear in all the tokens examined. The following occurrences, for instance, merely refer to the processes of knowing and forgetting taking place; there is no apparent implication of the subject, the experiencer or any other external factor triggering their development. The example in (43), which refers to the disposable coffee cup that was spotted in one of the episodes of the final season of the famous TV series Game of Thrones, is particularly illustrative in this regard since it highlights the accidental nature of the oversight:

(43) There is a reason for it: as more genes get known, more are the chances of the development of personalized medicines.

(44) [...] in an email GOT's art director Hauke Richter said "Things can get forgotten on set. The coffee cup error has been so blown out of proportion because it has not happened with 'Thrones' so far".

In these instances, there are no hints in the surrounding context that may lead to the identification of either the subject, the experiencer or any external circumstance having an influence on the bringing about of the process. Thus, even if this might really be the case, the ingressive and resultative components of the sentence become particularly salient, and responsibility, if there is any, is thus downplayed. While in (45), for instance, there is an 
explicit mention of the property of bathrooms responsible for them becoming forgotten when people decorate their homes - they are not central spaces in a house-, in (46) no open references to any possible factor prompting the process are found. Although it might be argued that the whole extract carries an implication of the people who own or live in the house being responsible for forgetting certain details, all the emphasis is put on the resulting state achieved by the bath towels, which is strengthened by the combination of the verb become and the adjective phrases dingy and frayed that follow the get-passive:

(45) On top of the layout limitations, the bathroom often gets forgotten simply because it's not a central space in the home. Kitchens, living rooms and bedrooms tend to take priority and it's usually the bathroom that gets pushed down the end of the list - or decorated halfheartedly.

(46) As winter grinds to a close, our focus will soon move from indoors to outdoors. Now is a great time to turn a critical eye on some of the winter-worn details in your home. [...] Bed pillows should be given a good look every other year, especially in a home with kids and pets. Bath towels get forgotten but can become dingy or frayed after years of use and laundering.

Such sentences, as Vanrespaille $(1991,106)$ points out regarding parallel instances of central get-passives, "focus on the result, responsibility not being the issue".

The lack of the responsibility reading has already been observed by some authors in central get-passives. In her diachronic corpus analysis of get constructions, Hundt (2001, 7576) finds several occurrences of get + past participle sentences with a clear passive function, i.e., instances where the subject is just an affected patient without responsibility for the action. Despite the existence of these neutral examples, however, Hundt concludes that central getpassives are likely to keep their responsibility reading. The analysis in Coto Villalibre (2015a, 187), on the contrary, points to the opposite direction: in his corpus study of central getpassives in four varieties of English (British, Indian, Hong Kong and Singaporean), nonresponsible subjects are more frequent than responsible ones. In his view, this shift from responsible to non-responsible subjects, together with the increase in the number of inanimate subjects, allows get-passives to perform new functions.

As regards cognitive get-passives, it is again worth pointing out the mixed behaviour of the verbs examined: Figure 5 shows that this meaning appears, though not very frequently, with forget, know and understand, but it has not been attested with believe and is very rare with remember. ${ }^{6}$

${ }^{6}$ The values for the verb understand in figures 2,3 and 5 are $53.3 \%, 33.3 \%$ and $13.3 \%$, respectively. Since the data in the charts has been rounded up to the whole number, these values add up to $99 \%$, not $100 \%$. 


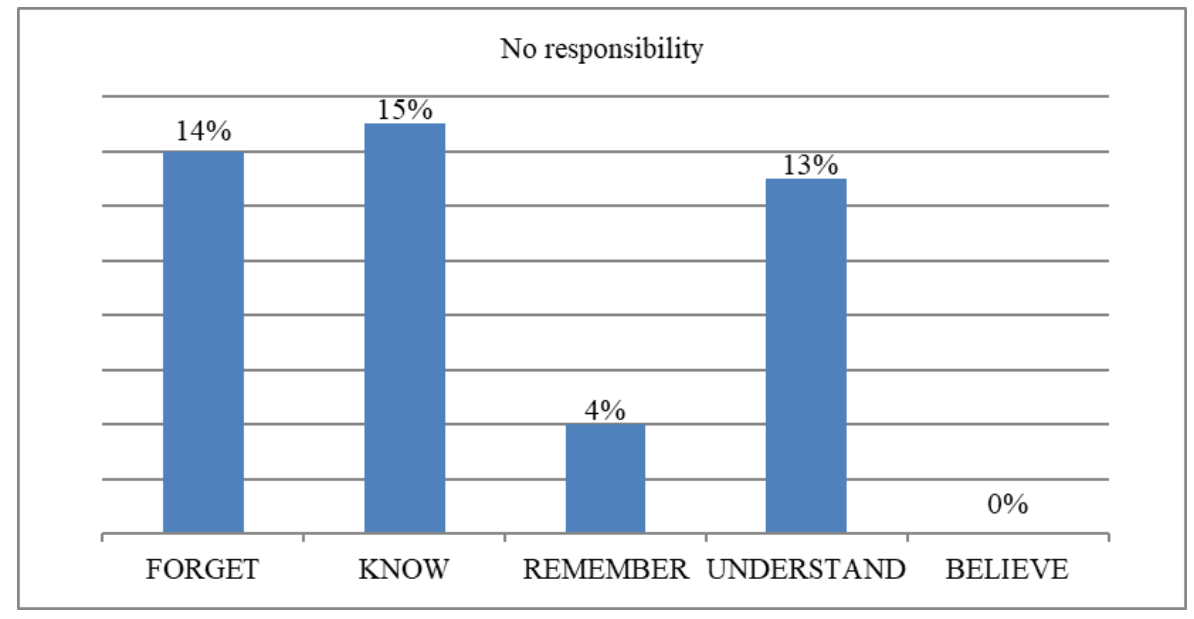

Figure 5. Distribution of tokens without responsibility reading

The findings set forth so far suggest a close connection between the notion of secondary responsibility and cognitive get-passives. However, there exist occurrences which lack implications of secondary responsibility, either assigned to the direct participants in the mental process or to external factors, and which only carry the central idea of change of state and result common to all get-passives.

\section{HUMAN AND INANIMATE SUBJECTS IN COGNITIVE GET-PASSIVES}

Previous corpus analyses maintain that central get-passives strongly favour an animate subject, specifically human. Arce-Arenales et al. $(1994,14)$, for instance, report that $88 \%$ of instances in their corpus has a human subject and relate this high number to the pseudoagentive nature of the subject: given the natural connection between agency, which implies control and responsibility, and humanness, the subjects of get-passives are more likely to be human. Similarly, Toyota $(2007,153)$ finds a human subject in $84.7 \%$ of the tokens in his corpus and argues that the get-passive presents the action from a human point of view and is thus more similar to the active voice than to the passive.

The analysis in 4.1. has showed that human as well as inanimate subjects may be interpreted as partially responsible for the outcome of the situation in cognitive get-passives. However, taking into account the natural link between the notion of responsibility and humanness, it may be worth considering whether human subjects, which may additionally exhibit intention and volition, will favour a responsibility reading more easily than inanimate subjects and will be, consequently, commoner than inanimate subjects in cognitive getpassives.

The correlation between humanness and responsibility appears to be borne out when looking at the data: Figure 6 shows that $64 \%$ of the total number of human subjects in the corpus are understood as partially responsible for the cognitive processes, while only $30 \%$ of inanimate subjects are assigned some kind of influence on them. 


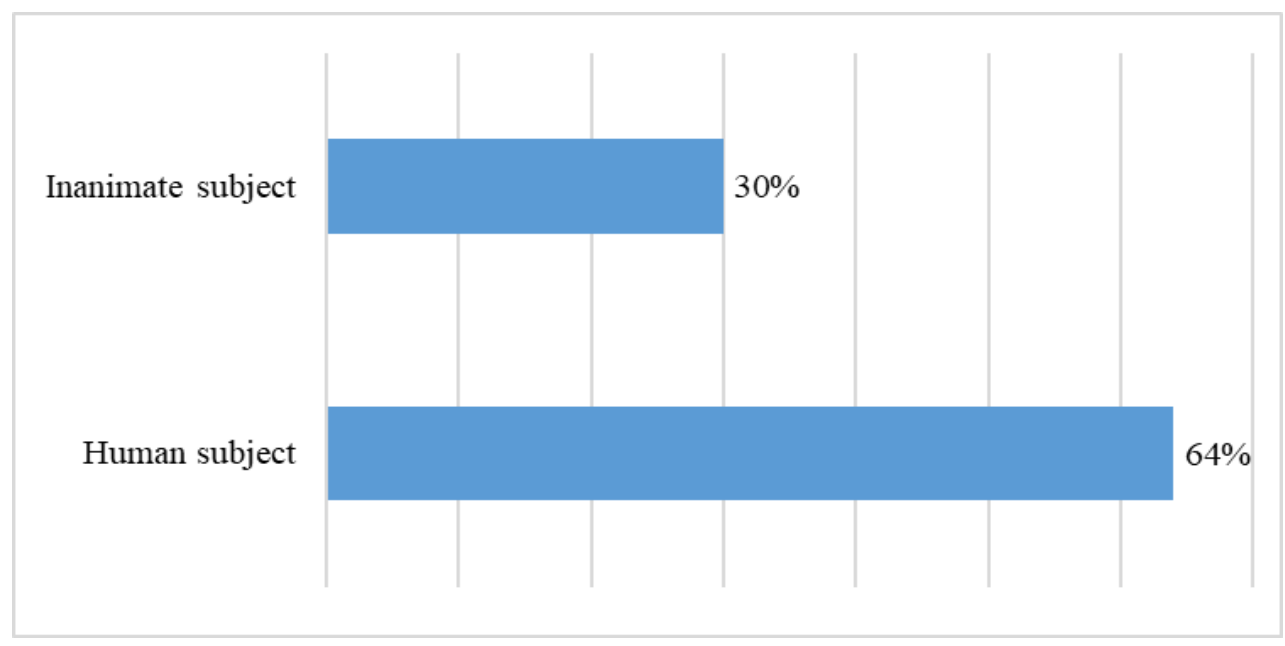

Figure 6. Overall distribution of the responsibility reading in human and inanimate subjects

The examination of the data indicates that human subjects in cognitive get-passives display a strong tendency to be interpreted as responsible for the event, while inanimate subjects, on the contrary, are less prone to be assigned such a reading. If, as many earlier studies have proposed, responsibility of the subject is a defining feature of get-passives, it should be reasonable to expect a much higher number of human than inanimate subjects in this construction. The analysis of our corpus, however, yields the opposite result: as shown in Figure 7, inanimate subjects outnumber human ones in cognitive get-passives.

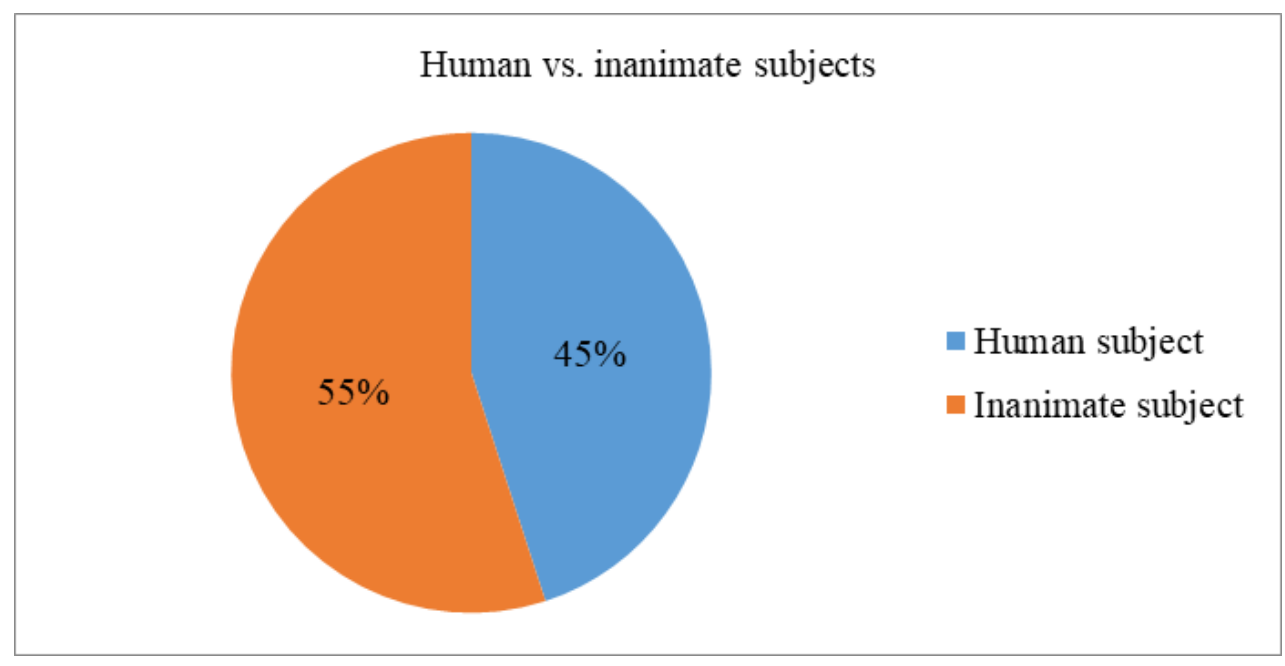

Figure 7. Distribution of human and inanimate subjects in the corpus

The higher number of inanimate subjects in the corpus can be derived from the lexical properties of the verbs analysed. If, as noted in many previous corpus studies (see Carter and McCarthy, 1999; Biber et al., 1999; or Kim, 2012, among others), the verbs most frequently used in central get-passives are dynamic predicates with a human object such as pay, catch, hit, arrest, or fire, this construction is expected to show a preference for human subjects. Verbs of cognition, on the contrary, allow for a wider range of objects. According to Halliday 
and Mathiessen $(2004,203)$, the class of participants that can be assigned the role of phenomenon with mental predicates "is not only restricted to any particular semantic or grammatical category, it is actually wider than the set of possible participants in a 'material' clause" and "maybe not only a thing but also and act or a fact". Consequently, the subject of cognitive get-passives exhibits a broad variety of referents: human beings (47), physical objects (48), abstract concepts (49), and even facts or states of affairs in the form of clausal subjects (50):

(47) Young, Old, Male, Female: This Is Who Gets Believed Least Online.

(48) Last-minute gifts are often the first thing to get forgotten.

(49) These figures of speech survive despite not being taught for 200 years [...] It's partly because when we do use or hear them, they get remembered.

(50) Whether this translates into a steep political cost or not will get known as the situation unfolds.

Besides the wide array of objects that verbs of cognition may take, the striking high frequency of inanimate subjects with the verb forget must be considered in order to account for the mismatch between central and cognitive get-passives: more than $72 \%$ of tokens with an inanimate subject in the corpus (491 out of 680) are occurrences with forget. If this verb is excluded from the count, the results come closer to the ones for central get-passive, $70 \%$ of the occurrences have a human subject, although they still do not match them fully. The apparent anomalous behaviour of forget nonetheless reinforces the connection between the subject's secondary responsibility and its frequent human nature. Since get-passives with forget are not commonly associated with the idea of the subject being responsible for initiating the forgetting event -only $24 \%$ of tokens exhibits this reading (see Figure 2) -, it is reasonable to expect a much higher number of inanimate subjects, which, as explained above, are less likely to be portrayed as partially responsible.

\section{6. $B Y$-PHRASE IN COGNITIVE GET-PASSIVES}

There is a common view on the low occurrence of by-agents in central get-passives. Collins (1996), Downing (1996) and Carther and McCarthty (1999), for instance, find that only about $8 \%-7 \%$ of get-passives in their corpora include an explicit agent. The lack of an overt agent has been attributed to the resultative meaning of the construction as well as to the notion of secondary responsibility of the subject: while Quirk et al. $(1985,161)$ argue that the syntactic absence of the agent draws attention to the subject and reinforces the idea of result, Wanner $(2009,104)$ claims that the lack of by-agents is to be expected since their explicit presence would interfere with the idea of the subject being responsible for the action. The analysis of the corpus of cognitive get-passives confirms this tendency: only $4 \%$ of tokens exhibit an overt by-experiencer. This unusual pattern is illustrated in the following examples: 
(51) Edward Norton's version of the smashing Hulk often gets forgotten by Marvel fans -and for good reason. Whereas Mark Ruffalo's bumbling interpretation of the character has a gravitational charm, Norton's moping monster is void of any charisma.

(52) That's the kind of legacy that should get remembered by everyday people [...].

Although Downing $(1996,192)$ also predicts that explicit agents will be infrequent in getpassives because of the emphasis that this construction places on the subject and what happens to it, she suggests that indefiniteness and inanimacy may favour the presence of an overt agent. Banks $(1985,128)$ similarly proposes that they may be possible if their anonymity is preserved. Experiencers in cognitive get-passives are, due to the nature of the processes they denote, always human. As regards the feature of indefiniteness, Figure 8 shows that indefinite and generic explicit experiencers such as Marvel fans in (51) and everyday people in (52) outnumber definite ones. ${ }^{7}$

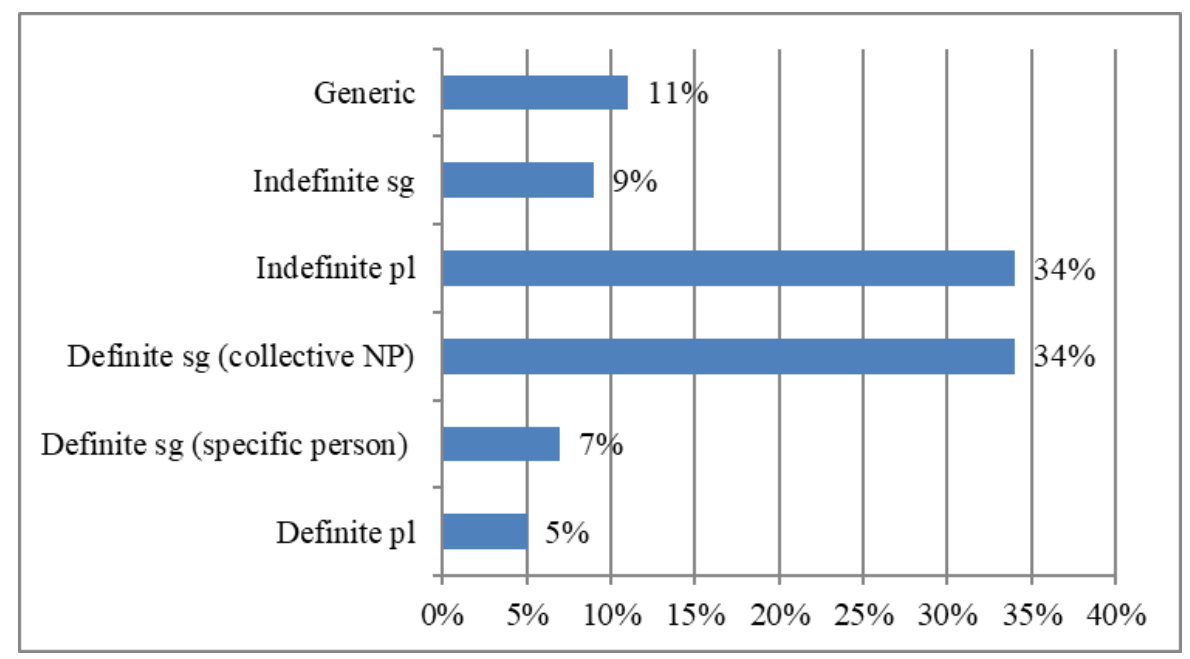

Figure 8. Explicit by-experiencers in cognitive get-passives

The contrast between indefinite and generic experiencers on the one hand, and definite experiencers on the other is not, however, as sharp as one might expect (54\% vs. 46\%). Nevertheless, it must be kept in mind that definite experiencers are mostly collective nouns such as community, public, government, press or audience in (53) whose level of

7 Hatcher $(1949,436$, fn. 4$)$ is one of the first authors who notes that the presence of human agents in the get-passive may depend on the degree of individuation of this participant and predicts that indefinite singular agents, such as the one in He got run over by a drunken drive, might be possible, whereas definite ones, as in He got run over by the man next door, would be hardly possible. The analysis of the corpus data confirms Hatcher's suggestions as regards the low degree of individuation of the implicit participant in get-passives, but it also shows that, as far as cognitive get-passives are concerned, this low degree of individuation is not expressed by means of indefinite singular experiencers but indefinite plural and generic ones which, as can be seen in figure 8 , are much more frequent. 
individuation is very low and, consequently, do not usually lessen the implication of the subject being partially responsible for the process: ${ }^{8}$

(53) This platform [TikTok] guarantees popularity for the people who want to be famous quickly and get known by a larger audience.

As already predicted for the explicit agent in central get-passives, overt definite experiencers referring to specific persons are least likely to occur in cognitive get-passives. Only three tokens, all of them with the verb forget as exemplified in (54), have been attested in the corpus:

\section{(54) No one ever got forgotten by Kristine.}

In these rare occurrences, responsibility is entirely assigned to the experiencer, not to the subject as in most instances of the construction. It is not surprising that definite experiencers only appear with forget since it is by far the most frequent verb in the corpus and the one most commonly associated with the reading in which the experiencer is portrayed as responsible for the process.

\section{ADVERSITY MEANING OF COGNITIVE GET-PASSIVES}

An adversity reading related to the expression of some unfortunate or unfavourable event is, together with the meaning of partial responsibility of the subject, usually cited as the most distinctive semantic feature of central get-passives. Givón and Yang (1994, 137-38), among many others, point out that the get-passive, as compared to the be-passive, has a strong tendency to display an adverse sense, depicting an "undesirable" resulting state. They even remark that the get-passive exhibits this adversity sense from its first attestations. Relatedly, Leech et al. $(2009,156)$ report that the get-passive is still mostly adversative in PDE and that this use has even slightly increased from the 1960 s to the $1990 \mathrm{~s}$.

Nonetheless, this distinct semantic association of the get-passive with an unfavourable event does not prevent it from expressing a positive outcome. Both Hatcher $(1949,441)$ and Chappell $(1980,417)$ claim that get-passives express situations with either adverse or beneficial effects on the subject, rather than neutral situations, and more recently Huddleston and Pullum (2002, 1442) agree on this dichotomous nature of the construction. Downing $(1996,196)$, on the other hand, finds that in contexts related to scientific, social, financial or educational issues the get-passive expresses a neutral condition.

The distribution of instances in the corpus points to a similar tendency in cognitive getpassives. The analysis of the data within the wider context where the tokens appear reveals

\footnotetext{
${ }^{8}$ An exception to this general trend will be nonetheless discussed in section 8 .
} 
that $58 \%$ convey a negative implication, $39 \%$ refer to a beneficial effect for the subject, and $3 \%$ are neutral:

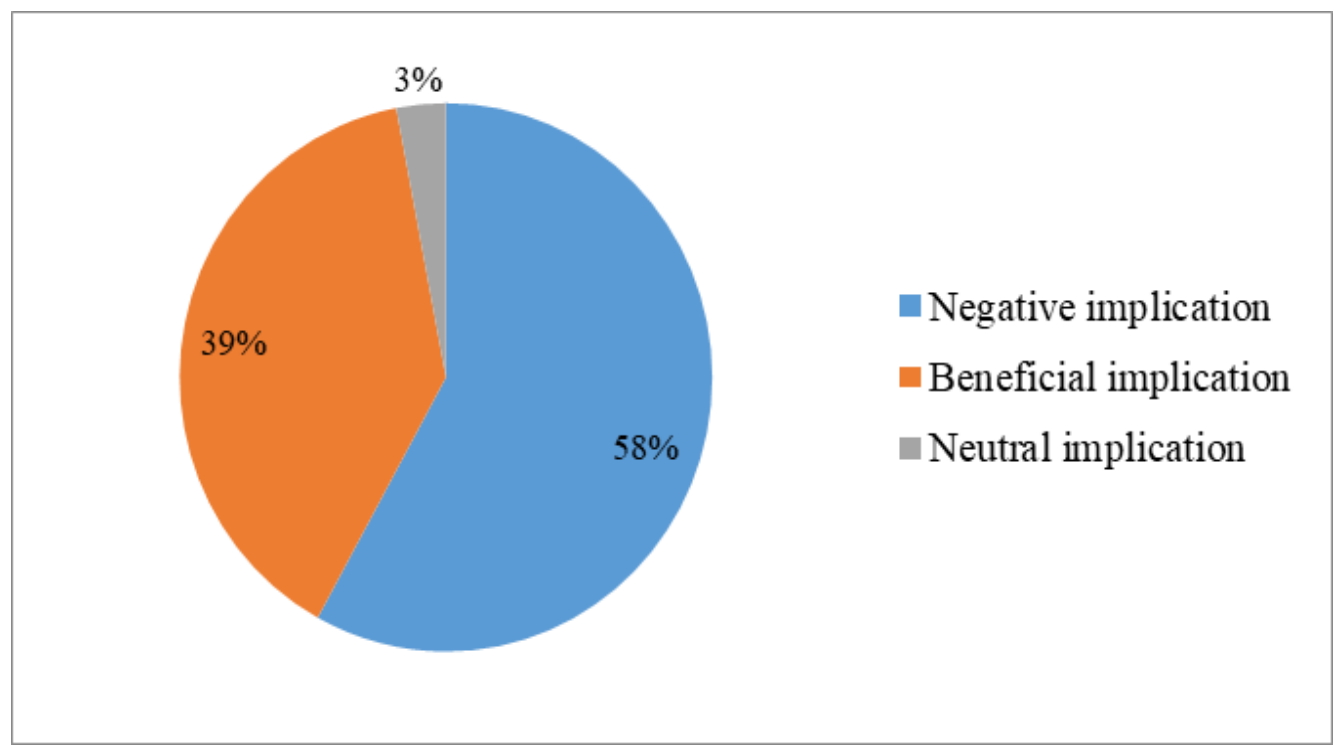

Figure 9. Semantic implications of cognitive get-passives

These results, however, cannot be taken as representative of the whole class since they show a strong lexical bias: the occurrences with forget, which can be claimed to refer to an unfavourable effect, are overwhelmingly associated with a negative reading, whereas those with know, remember and, to a lesser extent, understand, which can be regarded as denoting a favourable outcome, are mostly positive statements. The verb believe exhibits a more balanced behaviour, though negative tokens are still more numerous, and no occurrences with neutral meaning are attested:

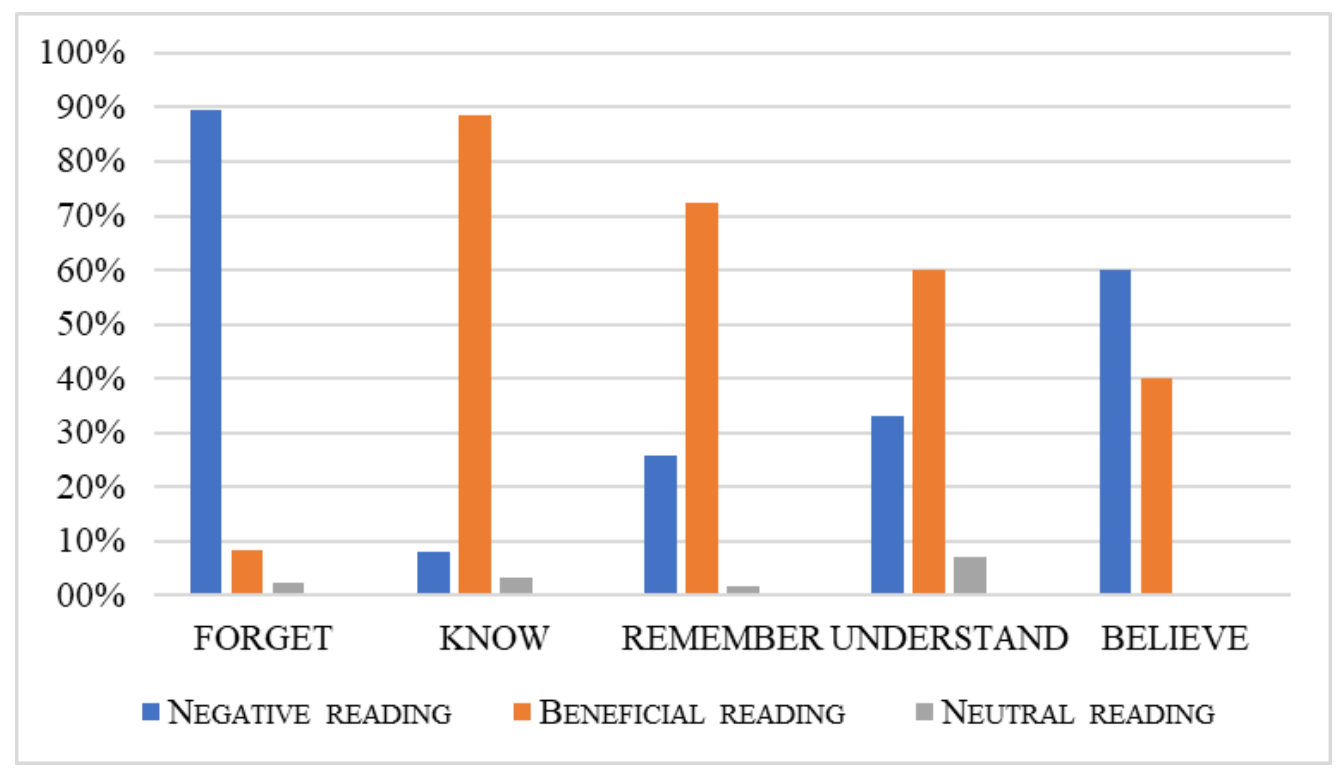

Figure 10. Distribution of negative, beneficial and neutral readings with each verb in the corpus 
The following examples illustrate the most common reading with each verb: get-passives with forget and believe most usually display a negative meaning, whereas occurrences with know, remember and understand commonly refer to a positive outcome:

(55) I was a scrawny little thing kid who was confused and depressed and had gotten forgotten in the divorce mess.

(56) The danger in this PR jargon is that it gets believed, leading to complacency and baddecision making.

(57) She succeeded in getting known with ambitious proposals and a scintillating and vibrating personality.

(58) When rock stars die, they aren't forgotten. Their hits get played, their influence gets noted, their biggest pop-culture moments get remembered. It will be no different for David Bowie.

(59) But what really distinguishes it from others is a sense of belonging. "Participants get community", Green says. "They get understood and they feel safe".

Notwithstanding this tendency to express detrimental or beneficial effects in accordance with the basic meaning of the verb, the reverse is also found. The tokens in (6o) and (61), for instance, show that getting forgotten is sometimes good while getting known does not always bring positive results:

(60) A medieval city as beautiful as Bruges but with a fraction of the tourist traffic, Ghent tends to get forgotten by the coach parties, and it's all the better for it.

(61) The Tories thought that Andrew would benefit from getting known, but the more people knew about him, the more they turn on him [...].

Although in the studies of the central get-passive it is widely assumed that the implication of fortunate or unfortunate consequences applies to the subject - or to its owner or creator when it is inanimate (see Hatcher, 1949, or Chappell, 1980)-, the data shows that other participants in the situation may be also affected. Human subjects, for instance, are sometimes identified with the speaker, who presents themselves as either positive or negatively affected by the process:

(62) In South Africa, if you get injured or play one or two bad games, they picked another guy and you can easily get forgotten.

The corpus also provides examples with a generic interpretation such as (63), which, unfortunately, predicts the effects that forgetting the past has meant for all human beings:

(63) The Spanish Flu, one of history's deadliest diseases, gets forgotten too easily [...] The Spanish Flu vividly teaches us that, as they say, we may be through with the past, but the past is not through with us. 
Neutral examples have also been attested although their proportion is very low: there are only 29 tokens of this kind, which amounts to approximately $3 \%$ of the corpus. A property shared by these occurrences is that all of them feature an inanimate subject, most usually with an abstract referent, and are frequently found in contexts related to politics, economics and judicial issues. In most cases, the meaning of partial responsibility is also absent so that only the ingressive and resultative senses of the subject "coming to be X-ed" are conveyed:

(64) Once the apex court decision on the pending list of 9 names gets known, high court collegium must recommend names for all available vacancies either in one or in more than one list.

All these observations suggest that, despite the clear preference of get-passives for verbs with an adversative core meaning such as kill, critise, accuse or beat commonly highlighted in the literature (see Carter and McCarthy, 1999; Biber et al., 1999; Rülhemann, 2007, or Phoocharoensil, 2020), the overall interpretation of the construction does not appear to be determined exclusively by the verb. Although the influence of the lexical meaning of the verb should not be overlooked because, as Collins $(1996,52)$ claims, it is the clearest indicator of a positive or negative reading, there are additional factors which play a significant role in the interpretation of cognitive get-passives. In this regard, Chappell $(1980,444)$ remarks that "verbs occurring in get-passives cannot be divided into an 'adversative' set and a 'beneficial' set. The speaker's intentions, aided by the context, determine which of the two interpretations is appropriate". The extremely high number of examples with forget in the corpus nonetheless points to a strong bias towards a negative interpretation in cognitive get-passives which is further favoured, as will be shown in the next section, by the speaker's emotional involvement and subjective attitude towards the situation depicted.

\section{SPEAKER'S INVOLVEMENT IN THE SITUATION}

A notion closely related to the adversity meaning of the get-passive and frequently considered in connection with it is what has been labelled "speaker's involvement in the situation". Lakoff $(1971,154)$ suggests that the get-passive usually reflects the attitude of the speaker towards the event, whether they feel it is good or bad. Similarly, Carter and McCarthy $(1999,51)$ claim that the get-passive focuses on the speaker attitude, judgement and affective posture towards the event and the subject. The speaker's stance is not necessarily conveyed either by get or by the participle but is to be found in the context.

Although usually, as Collins (1996, 52) highlights, we can only speculate about the speaker's approving or disapproving attitude, the information contained in the context surrounding cognitive get-passives in the present corpus often provides clear hints about it. Feelings of happiness, pride or gratitude such as the ones in (65) and (66), for instance, are not uncommon in sentences depicting a positive situation: 
(65) Maybe that's it, that I've always given it my all. If that's the way that I get remembered, that's great.

(66) I am getting known and all the people like me because I am India's representative today, and it's such a proud feeling.

The analysis of the data suggests, however, that occurrences which refer to a negative outcome, particularly those with forget, which is by far the most strongly linked to a negative interpretation, are frequently associated with a deep emotional involvement and often convey a strong sense of complaint, anger, admonition, reproach, apology, or fear:

(67) Scarborough is sort of the forgotten part of Toronto. The people of Scarborough contribute taxes just like everyone else does. The fact that they continue to get forgotten is something that frankly I am not going to allow to happen.

(68) What often gets forgotten is that if we find breast cancer at an early stage, saving a life is not the only benefit. 9

(69) Love is a verb, not a noun. It's a doing word and that's what gets forgotten. Love isn't just a seed you plant in the ground and watch it automatically grow. You have to tend to it.

(70) You might get forgotten sometimes. Not because I don't love you, but because I've got the weight of the $\mathrm{f}^{* * *}$ ing world on my shoulders.

(71) In talent shows nine times out of 10, winners and runners-up vanish after a couple of years [...] My biggest fear was I'd get forgotten and not work again.

The most noteworthy feature of these occurrences is that responsibility is assigned to the implicit experiencer of the cognitive process and, due to the speaker's negative attitude implied, the construction indirectly blames this participant for the negative consequences of the situation. Occasionally, the experiencer is identified with a group of people who, despite not being overtly expressed as a by-phrase, is easily recognised by the linguistic context and directly accused of being responsible for the detrimental situation:

(72) Administrations, both Democrat and Republican, have promised to deliver change. Every election they campaign on it, then they get elected and middle America gets forgotten.

This implication is even stronger in a few examples with an explicit by-experiencer, as (73), where this participant is openly identified as responsible for the negative consequences of the event, carrying thus an even stronger sense of discontent and disapproval:

(73) So a shrine holding Peter's bones in the basilica somehow gets forgotten - by the very church which regards Peter as its founder and designates the pope as his successor- and is not rediscovered until 1940? Unbelievable.

9 The expression what (often) gets forgotten is [...] is a frequent way of introducing these tokens, which reinforces the sense of the speaker's involvement. 
This use of the get-passive as a device to accuse the experiencer for the adverse effects of the situation was already pointed out by Lakoff (1971) in relation to central get-passives and may account for the high number of occurrences of cognitive get-passives with the verb forget mentioned above where partial responsibility is linked to the experiencer (see Figure 3). Moreover, the meaning of forget in this usage is not the usual, more neutral sense "to lose remembrance of; to cease to retain in one's memory" or "to omit to take, leave behind inadvertently" as in many other tokens in the corpus, but the clear negative meaning "to cease or omit to think" or "to omit or neglect through inadvertence" ("forget, v", 2020). The semantic richness of forget together with its negative meaning and its common association with the speaker's strong emotional involvement may explain why it is much more frequent in the corpus than any of the other verbs analysed.

\section{CONCLUDING REMARKS}

This corpus analysis of get-passive constructions with the cognition verbs forget, know, remember, believe and understand has confirmed that, contrary to the mainstream opinion, they are possible although extremely infrequent in PDE. It must be emphasized however, that the verb forget exhibits, as compared with the other four verbs analysed, a remarkable high frequency. Thus, the data has amply shown that, as $\operatorname{Kim}(2012,11)$ remarks on some occasional occurrences of what I have called cognitive get-passive he attests in the COCA corpus, "their uses cannot be taken to be errors".

Regarding the semantic and pragmatic features that best describe cognitive get-passives, the examination of the corpus has revealed that their most defining feature is their primary ingressive and resultative meanings, which are present in all the sentences analysed. As frequently noted in the literature on the central type, cognitive get-passives also focus on the result of the event and always carry the implication of the subject "coming to be X-ed" (Vanrespaille, 1991; Downing, 1996). Building on observations by Martínez Vázquez (1989) and Kim (2012) regarding the aspectual properties of the get-passive and on the results of Schwarz's (2017 and 2019) corpus analysis, the present work has confirmed Kim's proposal that the get-passive has a coercion effect on the verbs that appear in the construction which makes them express telic process, regardless of whether they are originally telic or atelic predicates. As for the cognitive verbs analysed here, it has been proposed that, even though they are inherently atelic, the get-passive construction provides them with a culminating point represented by the resulting state reached by the subject due to the mental process denoted.

Alongside this pervading sense of significant result, the analysis has shown that this central semantic component is enriched by additional meanings. Among them, one of the most noteworthy is the sense of secondary responsibility of the subject, which has been widely attested in the corpus. The data examined has also evidenced that this notion must be expanded so that it could include the implication of the experiencer or some external circumstance triggering the development of the mental process, being, consequently, partially responsible for its effects on the subject or some person related to it. This reading, however, 
does not appear in all the occurrences, which may support the claim put forward by previous studies that responsibility is not an integral part of the get-passive, but only an implicature (Huddleston and Pullum, 2002; Wanner, 2009 and 2013, or Gotowski, 2016).

The semantic richness of cognitive get-passives has also been observed in the fact that they are not primarily used to communicate a neutral condition; they rather convey negative or beneficial implications although, as in central get-passives, negative ones are more frequent. These implications, however, are highly sensitive to the context and are not a priori determined by the core meaning of the verb. This fact may indicate that, as Huddleston and Pullum (2002), Guerrero Medina (2009), Wanner (2009) and (2013), or Coto Villalibre (2015b) have already suggested, the predominant negative reading is again a possible implicature but is not built into the construction. Finally, the analysis has confirmed that many, but not all, cognitive get-passives reflect the speaker's strong emotional involvement. This feature, as frequently remarked in the studies of the central get-passive, is closely associated to the widespread adversative connotations and is likewise highly contextdependent.

The data examined has also shown that the features just discussed are not isolated components; on the contrary, they frequently overlap and combine in a tight way. Additionally, it has been observed that the verbs analysed do not exhibit these properties to the same extent, which suggests that the lexical properties of the verb play a significant role in the use of cognitive get-passives. Particularly remarkable in this sense is the behaviour of forget: it represents a departure from the most usual get-passive with partially responsible subjects as it presents the lowest number of this kind of subjects but is by far the most frequently attested in the corpus. It has been proposed that this extraordinary high frequency is derived from the interaction of three factors that usually appears in the construction together with the central ingressive and resultative values: the assignment of responsibility to the (implicit) experiencer, the negative implications which arise from the versatile meaning of the verb and the strong emotional involvement of the speaker. All this makes the get-passive with forget a powerful device to express a wide variety of negative feelings and to indirectly, or sometimes even directly, blame the experiencer for the detrimental effects of the process.

Lastly, with regards their formal properties, it can be concluded that cognitive getpassives, contrary to the central type, exhibit a marked preference for inanimate subjects, probably due to the lexical properties of the verbs involved, which allow for a wider variety of transitive objects than the verbs typically found in central get-passives, and the high number of tokens with the verb forget, which amply favours inanimate subjects. In accordance with central get-passives, nonetheless, cognitive get-passives most usually appear without an explicit by-phrase and, when it appears, it is mostly indefinite and collective. 


\section{REFERENCES}

Alexiadou, A. 2005. "A Note on Non-Canonical Passives: The Case of the Get-Passive", in Broekhuis, H., Corver, N., Huybregts, R., Kleinhenz, U., Koster, J. and Huijbregts, R. (eds.), Organizing Grammar: Linguistic Studies in Honor of Henk van Riemsdijk. Berlin \& New York: De Gruyter Mouton, pp. 13-21.

ANDERWALD, L. 2017. "GET, GET-Constructions and the GET-Passive in 19th-Century English: Corpus Analysis and Prescriptive Comments", in Hoffmann, S., Sand, A. and Arndt-Lappe, S. (eds.), Exploring Recent Diachrony: Corpus Studies of Lexicogrammar and Language Practices in Late Modern English. Helsinki: Helsinki University. Retrieved from https://varieng.helsinki.fi/series/volumes/18/anderwald/.

Arce-Arenales, M., Axelrod, M. and Fox, B. A. 1994. "Active Voice and Middle Diathesis. A Cross-Linguistic Perspective”, in Fox, B. A. and Hopper, P. J. (eds.), Voice: Form and Function. Amsterdam/Philadelphia: John Benjamins, pp. 1-21.

BANKS, D. 1985. "Getting by with GET”, La Linguistique, 22(1), pp. 125-130.

BIBER, D., CONRAD, S. and LEECH, G. 1999. Longman Grammar of Spoken and Written English. London: Longman.

BINNICK, R. I. 2006. "Aspect and Aspectuality", in Aarts, B. and McMahon, A. (eds.), The Handbook of English Linguistics. London: Blackwell, pp. 244-268.

CARTER, R. and MCCARTHY, M. 1999. "The English Get-Passive in Spoken Discourse: Description and Implications for an Interpersonal Grammar”, English Language \& Linguistics, 3(1), pp. 41-58. https://doi.org/10.1017/S136067439900012X.

Chappell, H. 1980. "Is the Get-Passive Adversative?”, Papers in Linguistics: International Journal of Human Communication, 13 (3), pp. 411-452. https://doi.org/10.1080/ 08351818009370504.

Collins, P. C. 1996. “Get-Passives in English”, World Englishes, 15(1), pp. 43-56. https://doi.org/ 10.1111/j.1467-971X.1996.tbooo91.x.

COMrie, B. 1976. Aspect. An Introduction to the Study of Verbal Aspect and Related Problems. Cambridge: Cambridge University Press.

Coto Villalibre, E. 2015a. "The 'Fading' of the Definitory Characteristics of Get-Passives: An Outer Circle Innovation?”, in Lázaro Lafuente, A. and Porto Requejo, M. D. (eds.), English and American Studies in Spain: New Developments and Trends. Alcalá de Henares: Universidad de Alcalá de Henares, pp. 181-188.

Coto Villalibre, E. 2015b. "Is the Get-Passive Really that Adversative?”, Miscelánea. A Journal of English and American Studies, 51, pp. 13-30. Retrieved from https://www. miscelaneajournal.net/index.php/misc/article/view/293/147.

DAVIES, M. 2016. Davies, Mark. (2016-) Corpus of News on the Web (NOW). Retrieved from https://www.english-corpora.org/now/.

DeClerCK, R., REED, S. and CAPPELle, B. 2006. The Grammar of the English Tense System: A Comprehensive Analysis. Berlin/New York: Mouton de Gruyter. 
Downing, A. 1996. “The Semantics of Get-Passives", in Hasan, R., Cloran, C. and Butt, D. G. (eds.), Functional Descriptions. Theory in Practice. Amsterdam/Philadelphia: John Benjamins, pp. 179-205.

Fleisher, N. 2006. "The Origins of Passive Get", English Language and Linguistics, 10(2), pp. 225-252. https://doi.org/10.1017/S1360674306001912.

"forget, v." 2020. Oxford English Dictionary Online. Oxford: Oxford University Press. Retrieved from https://www.oed.com/.

Givón, T. and YANG, L. 1994. "The Rise of the English GET-Passive", in Fox, B. and Hopper, P. J. (eds.), Voice: Form and Function. Amsterdam/Philadelphia: John Benjamins, pp. 119-149.

GotowsKi, M. K. 2016. "Secondary Agents in Get-Passives: Syntax or Pragmatics?”, Proceedings of the Third Linguistics Conference at the University of Georgia, pp. 1-10. Retrieved from https://athenaeum.libs.uga.edu/bitstream/handle/10724/38034/CP2016_Gotowski.pdf?se quence $=1$ \&isAllowed $=\mathrm{y}$.

Guerrero Medina, P. 2009. "Semantic and Pragmatic Constraints on the English Get-Passive", in Buttler, C. S. and Martín Arista, J. (eds.), Decontrasting Constructions. Amsterdam/ Philadelphia: John Benjamins, pp. 271-294.

Halliday, M. A. K. and Matthiessen, C. M. I. M. 2004 (1985). An Introduction to Functional Grammar. London: Hodder Arnold.

HAtcher, A. G. 1949. "To Get/Be Invited", Modern Language Notes, 64(7), pp. 433-446. https://doi.org/10.2307/2910009.

Huddleston, R. and Pullum, G. K. 2002. The Cambridge Grammar of the English Language. Cambridge: Cambridge University Press.

HundT, M. 2001. "What Corpora Tell Us about the Grammaticalisation of Voice in GetConstructions", Studies in Language, 25(1), pp. 49-88. https://doi.org/10.1075/ sl.25.1.o3hun.

JeSPERSEN, O. 1949. A Modern English Grammar on Historical Principles. Part IV, Syntax. Vol. 3. London: George Allen \& Unwin Ltd.

KIM, J.-B. 2012. "English Get-Passive Constructions: A Corpus-Based Approach", Studies in Generative Grammar, 22(2), pp. 437-457. Retrieved from http://web.khu.ac.kr/ jongbok/research/2012/2012-dom-get.passive.pdf.

LAKOFF, R. 1971. "Passive Resistance", Papers from the Seventh Regional Meeting of the Chicago Linguistic Society. Chicago: Chicago Linguistic Society, pp. 149-162.

LANGACKER, R. W. 1991. Concept, Image and Symbol. The Cognitive Basis of Grammar. Berlin: Mouton de Gruyter.

Leech, G., Hundt, M., Mair, C. and Smith, N. 2009. Change in Contemporary English. A Grammatical Study. Cambridge: Cambridge University Press.

Lindstromberg, S. 1999. "Get: Not Many Meanings", International Review of Applied Linguistics, 29(4), pp. 285-301. https://doi.org/10.1515/iral.1991.29.4.285.

MAIR, C. and LEECH, G. 2006. "Current Changes in English Syntax", in McMahon, A. and Aarts, B. (eds.), The Handbook of English Linguistics. London: Backwell, pp. 318-342.

MARTÍNEZ VÁZquEZ, M. 1989. "Valores aspectuales de get + participio pasivo en el inglés actual", Anuario de Estudios Filológicos, 12, pp. 187-195. 
Mitkovska, L. and BuŽArovska, E. 2012. "An Alternative Analysis of the English Get-Past Participle Constructions: Is Get All That Passive?”, Journal of English Linguistics, 40(2), pp. 196-215. https://doi.org/10.1177/o075424211418978.

Palmer, F. R. 1988 (1974). The English Verb. London: Longman.

Phoocharoensil, S. 2020. "English Get-Passives: Reassessing the Frequencies across Genres", GEMA Online Journal of Language Studies, 20(3), pp. 123-135. http://dx.doi.org/ 10.17576/gema-2020-2003-08.

QUirk, R., Greenbaum, S., LEeCH, G. and Svartvik, J. 1985. A Comprehensive Grammar of the English Language. London: Longman.

RÜHLEMANN, C. 2007. "Lexical Grammar: the GET-Passive as a Case in Point", ICAME Journal, 31, pp. 111-127. Retrieved from https://www.uni-marburg.de/de/fb1o/iaa/institut/ personen/ruehlemann/lexical_grammar-proofs5.pdf.

SCHWARZ, S. 2017. "'Like Getting Nibbled to Death by a Duck'. Grammaticalization of the GETPassive in the TIME Magazine Corpus", English World-Wide, 38(3), pp. 305-355. https://doi.org/10.1075/eww.38.3.03sch.

SchwarZ, S. 2019. "Signs of Grammaticalization. Tracking the GET-Passive through COHA", in Claridge, C. and Bös, B. (eds.), Developments in Historical Morpho-Syntax. Amsterdam/ Philadelphia: John Benjamins, pp. 199-221.

SMITH, C. S. 1991. The Parameter of Aspect. Dordrecht: Foris.

Thompson, D., Ling, S. P., Myachykov, A., Ferreira, F. and ScheEPERs, C. 2013. "Patient-Related Constraints on Get- and Be-Passive Uses in English: Evidence from Paraphrasing”, Frontiers in Psychology, 4, pp. 1-24. https://doi.org/10.3389/fpsyg.2013.00848.

Thompson, D. and ScheEPERs, C. 2013. "Harmonizing the Passive: A New Proposal for Passive Constructions in Generative Grammar”, Newcastle Working Papers in Linguistics, 19(2), pp. 74-95.

ToYotA, J. 2007. "An Adversative Passive in English: in Search of Origins", in Delbecque, N. and Cornillie, B. (eds.), On Interpreting Construction Schemas: From Action and Motion to Transitivity and Causality. Berlin \& New York: De Gruyter, pp. 143-169.

VANRESPAILle, M. 1991. "A Semantic Analysis of the English Get-Passive", INTERFACE. Journal of Applied Linguistics, 5(2), pp. 95-112.

Vendler, Z. 1957. "Verbs and Times", The Philosophical Review, 66(2), pp. 143-160. https://doi.org/10.2307/2182371.

WANnER, A. 2009. Deconstructing the English Passive. Berlin \& New York: De Gruyter.

WANnER, A. 2013. "The Get-Passive at the Intersection of Get and the Passive", in Alexiadou, A. and Schäfer, F. (eds.), Linguistik Aktuell/Linguistics Today: Non-Canonical Passives. Amsterdam/Philadelphia: John Benjamins, pp. 43-61.

YoneKuRA, Y. 1999. "On the Semantic Development of Get", Osaka University Papers in English Linguistics, 4, pp. 205-229. https://doi.org/10.18910/72948. 


\section{ACKNOWLEDGEMENTS}

The research reported in this article was conducted within the framework of Project UPO-1254742, funded by the European Regional Development Fund (80\%) and the Regional Government of Andalusia (FEDER Andalucía 2014-2020).

\section{ABOUT THE AUTOR}

Luisa González Romero holds a PhD in English Philology and is Associate Professor at the Universidad de Huelva (Spain), where she teaches courses on English syntax and theoretical linguistics. She has participated in three R\&D projects and her main areas of research are contrastive grammar English-Spanish and corpus linguistics. ORCID: 0000-0002-8001-6672 